\title{
The clinical outcomes of oldest old patients
tuberculosis treated by regimens containing rifampicin, isoniazid, and pyrazinamide
}

\author{
Huang-Shen $\operatorname{Lin}^{1,2}$ \\ Chun-Wen Cheng ${ }^{3}$ \\ Ming-Shyan Lin ${ }^{4}$ \\ Yen-Li Chou ${ }^{5}$ \\ Pey-Jium Chang ${ }^{2}$ \\ Jing-Chi Lin ${ }^{6}$ \\ Jung-Jr $\mathrm{Ye}^{3}$
}

'Division of Infectious Diseases, Department of Internal Medicine,

Chang Gung Memorial Hospital,

Chia-Yi, ${ }^{2} \mathrm{Graduate}$ Institute of Clinical

Medical Sciences, College of Medicine,

Chang Gung University, Taoyuan,

${ }^{3}$ Division of Infectious Diseases,

Department of Internal Medicine,

Chang Gung Memorial Hospital

at Linkou, Chang Gung University

College of Medicine, Taoyuan,

${ }^{4}$ Division of Cardiology, Chang Gung

Memorial Hospital, Yunlin, ${ }^{5}$ Division

of Pulmonary and Critical Care

Medicine, Department of Internal

Medicine, Chang Gung Memorial

Hospital, Chia-Yi, ${ }^{6}$ Division of Allergy

and Immunology and Rheumatology,

Department of Internal Medicine,

Chang Gung Memorial Hospital,

Chia-Yi, Taiwan
This article was published in the following Dove Press journal:

Clinical Interventions in Aging

II March 2016

Number of times this article has been viewed

Objectives: To investigate the clinical characteristics, adverse drug reactions, and outcomes of the oldest old patients (aged $\geq 80$ years) with tuberculosis (TB) treated with rifampicin, isoniazid, and pyrazinamide (RIP)-containing regimens.

Design: A retrospective chart review study.

Setting: A 1,200-bed tertiary teaching hospital in southwest Taiwan.

Participants: We conducted a retrospective observational study between January 1, 2005 and December 31, 2011. Seven hundred adult patients (aged $\geq 18$ years) with TB treated with RIP-containing anti-TB regimens were reviewed, including 161 oldest old patients.

Outcome measures: Clinical outcomes included clinical responsiveness and microbiological eradication. Adverse outcomes included drug-induced hepatitis, and other symptoms included gastrointestinal upset (eg, abdominal pain, vomiting, diarrhea, or dyspepsia), skin rash, joint pain, and hyperuricemia.

Results: Compared with the non-oldest old adult patients, the oldest old patients more frequently had hepatitis $(P=0.014)$, gastrointestinal upset $(P=0.029)$, and unfavorable outcomes $(P<0.001)$. In a multivariate analysis, hepatitis during treatment (adjusted odds ratio: 3.482 , 95\% confidence interval: $1.537-7.885 ; P<0.003$ ) and oldest old age (adjusted odds ratio: 5.161 , 95\% confidence interval: $2.294-11.613 ; P<0.010)$ were independent risk factors for unfavorable outcomes. In the oldest old patients with hepatitis, rifampicin use was more common in the favorable outcome group than in the unfavorable outcome group ( $100 \%$ vs $37.5 \%$; $P=0.001$ ). Conclusion: The oldest old age and hepatitis during RIP treatment were associated with unfavorable outcomes. For the oldest old patients with TB having hepatitis during treatment, rifampicin rechallenge and use might benefit the treatment outcome.

Keywords: hepatitis, refampicin, adverse effect

\section{Introduction}

Tuberculosis (TB) remains a major problem in both developing and developed countries. In 2014, an estimated 9.6 million new cases occurred worldwide. ${ }^{1}$ Although the annual TB incidence decreased slightly in some developed areas of the world, it continued to increase in developing countries. This increase has been more profound in the elderly population than in other age demographics in some area, such as the Eastern Mediterranean and the Western Pacific regions. ${ }^{1,2}$

A global demographic analysis found that "oldest old" individuals (aged $\geq 80$ years) is the fastest growing demographic. In 2004, the oldest old comprised $18 \%$ of the world's older people and $24 \%$ of people in more developed countries, and the proportion of the oldest old people will continue to increase during the next 2 decades. ${ }^{3}$
Correspondence: Jung-Jr Ye

Division of Infectious Diseases,

Department of Internal Medicine, Chang

Gung Memorial Hospital at Linkou,

Chang Gung University College of

Medicine, 5 Fu-Shin Street, Gueishan 333,

Taoyuan, Taiwan

Tel $+8863328 I 200$ ext 8450

Fax +88633289410

Email loyalwise@gmail.com
Clinical Interventions in Aging 2016: I I 299-306

(c) (1) (8) ( 2016 Lin et al. This work is published and licensed by Dove Medical Press Limited. The full terms of this license are available at https://www.dovepress.com/terms.php (c). hereby accept the Terms. Non-commercial uses of the work are permitted without any further permision from Dove Medical Press Limited, provided the work is properly attributed. For permisision

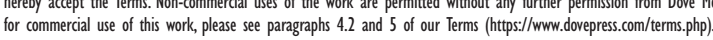

Dovepress

http://dx.doi.org/10.2147/CIA.S9541। 
In $2014,25 \%$ of older people (aged $\geq 65$ years) were oldest old in Taiwan. ${ }^{4}$ Previous studies have reported that elderly patients with TB (aged $\geq 65$ years) exhibit unusual clinical manifestations, delayed diagnoses, and higher rates of adverse drug reactions and unfavorable outcomes. ${ }^{5-11}$ However, the published data for the oldest old patients with TB are limited. ${ }^{12,13}$ This retrospective study was conducted to investigate the clinical characteristics, adverse drug reactions, and outcomes of the oldest old patients with TB treated with rifampicin, isoniazid, and pyrazinamide (RIP)-containing regimens.

\section{Methods}

\section{Study design and patients}

Chang Gung Memorial Hospital at Chia-Yi, Taiwan, is a 1,200bed tertiary teaching hospital in southwest Taiwan. A retrospective study of all adult patients with TB (aged $\geq 18$ years) diagnosed in this hospital between January 1, 2005, and December 31, 2011 with positive Mycobacterium tuberculosis complex (MTB) cultures initially treated with RIP in the presence or absence of ethambutol therapy was carried out. Patients who died in the first 2 months or were lost to follow-up, those with human immunodeficiency virus infection, and those who had undergone organ transplantation were excluded. Both the electronic and paper charts of the study patients were reviewed. The data were analyzed with delinking from the patient's privacy information. This study was approved by the Institutional Review Board of the Chang Gung Memorial Hospital (Number: 100-0873B). The ethics committee granted a waiver for informed consent to be obtained.

\section{Demography, comorbidity, and constitutional symptoms}

Data regarding age, sex, and comorbid conditions were gathered by reviewing the patients' medical records. Patients aged $\geq 80$ years were classified as the "oldest old group" and patients aged 18-79 years were the "non-oldest old adult patient group." The verified comorbidities included diabetes mellitus, heart disease, COPD, stage V chronic kidney disease, decompensated liver cirrhosis, and solid organ or hematological malignancy. Patients who were serologically positive for the hepatitis B virus (HBV) surface antigen and anti-hepatitis $\mathrm{C}$ virus (anti-HCV) antibody were recorded as HBV carriers and HCV-seropositive patients, respectively. The constitutional symptoms included fever, body weight loss, and cold sweating.

\section{Diagnosis}

All patients with TB infections were diagnosed according to positive MTB cultures; those infected with rifampicin-resistant and high-level isoniazid $(10 \mu \mathrm{g} / \mathrm{mL})$-resistant pathogens were excluded from the study.

Pulmonary TB was defined as an MTB-positive lower respiratory tract culture; this included cultures from sputum, tracheal aspirates, bronchoalveolar lavage fluid, and lung tissue. Pleural TB was defined as an MTB-positive pleural effusion or pleural tissue culture. Upper respiratory tract TB was defined as an MTB-positive upper respiratory tract culture; these included specimens from the larynx, tonsils, and nasopharynx. Bone and joint TB, including TB arthritis, was defined as an MTB-positive synovial fluid culture, and spinal TB was defined as an MTB-positive paraspinal abscess, epidural abscess, or spinal bone tissue culture. Other sites of infection were determined by positive MTB cultures from corresponding organ systems. Disseminated TB was defined as TB involvement in at least two organ systems.

\section{Treatment, adverse drug reactions, and outcomes}

First-line anti-TB treatment was defined as the use of at least two of the RIP component drugs, and second-line treatment was defined as the use of alternative therapy. Patients who either temporarily or permanently discontinued or changed their therapeutic medicines were suspected of having adverse drug effects. ${ }^{14}$ Patients were able to take certain anti-TB drug continuously after such represcribed drug was defined as a successful rechallenge. A hepatitis diagnosis required one of the following conditions: 1) a transaminase level increase of $>5$-fold above the normal upper limit; 2) a transaminase level increase of $>3$-fold above the normal upper limit with hepatitis-associated symptoms (eg, nausea, vomiting, abdominal tenderness, discomfort near the ribs on the right upper abdomen, and jaundice); or 3) a total bilirubin level of $>3 \mathrm{mg}$ / $\mathrm{dL}$ with hepatitis-associated symptoms. The durations between the initiation of anti-TB therapy and the onset of hepatitis were classified as $<2$ months, 2-4 months, and $>4$ months. The numbers and types of TB medications were discontinued after hepatitis, and the rates of successful rechallenge were recorded. Other adverse drug reactions included gastrointestinal upset (eg, abdominal pain, vomiting, diarrhea, or dyspepsia), skin rash, joint pain, and hyperuricemia. Patients who received a full course of TB treatment with good clinical responsiveness and microbiological eradication were considered as having favorable outcomes. Patients who died during therapeutic course were designated as having unfavorable outcomes. 


\section{Hepatitis management during RIP treatment}

Management was divided into either successful first-line anti-TB rechallenge (atleast two components of the RIP) or second-line anti-TB drug therapy (including more than two second-line bactericidal anti-TB agents or one RIP component plus another second-line bactericidal anti-TB drug) or a failure to rechallenge (mortality before anti-TB drug rechallenge). In the case of successful rechallenge, the duration was classified as either $<1$ months or $\geq 1$ month ( $\geq 2$ types of bactericidal anti-TB drugs). Each patient's tolerance for the individual components of RIP without discontinuation and successful rechallenge was recorded.

\section{Statistical methods}

All statistical analyses were performed using the Statistical Package for the Social Sciences for Windows (Version 18.0; SPSS Inc., Chicago, IL, USA). Categorical variables were compared using the $\chi^{2}$ test or Fisher's exact test as appropriate. Odds ratios (ORs) and 95\% confidence intervals (CIs) were calculated. Variables with $P$-value $<0.1$ in the univariate analysis and other variables of interest were included in a logistic regression model for the multivariate analysis. All tests were two tailed, and a $P$-value $<0.05$ in the multivariate analysis was considered significant.

\section{Results}

\section{Demography, comorbidity, and constitutional symptoms}

A total of 700 adult patients with culture-positive TB infections were included in this study, including 161 oldest old patients $(23.0 \%)$. The mean age of the 700 patients was 67.3 years with male predominance $(75.7 \%)$. The comorbidity and constitutional symptoms are listed in Table 1. Compared with the non-oldest old adult patients, the oldest old patients were mostly women $(34.2 \%$ vs $21.3 \%$; $P=0.001)$, with a higher rate of COPD $(8.1 \%$ vs $3.5 \% ; P=0.015)$ and lower rates of hepatitis B positivity $(9.2 \%$ vs $23.4 \%$; $P=0.007)$ and body weight loss $(6.2 \%$ vs $19.5 \% ; P<0.001$; Table 1).

\section{Sites of infection}

Pulmonary TB was the most common diagnosis (93.7\%); the other sites of infection are listed in Table 1. Compared with the non-oldest old adult patient group, the oldest old group had a higher incidence of bone and joint TB (7.1\% vs 3.4\%; $P=0.037$; Table 1).

\section{Adverse effects}

Hepatitis (11.9\%) was the most common etiology of anti-TB drug discontinuation in our study. Other adverse reactions are listed in Table 1. Compared with the non-oldest old adult patient group, the oldest old group had higher rates of hepatitis $(17.4 \%$ vs $10.2 \% ; P=0.014)$ and gastrointestinal upset $(5.0 \%$ vs $1.9 \% ; P=0.029$; Table 1$)$.

\section{Outcome}

Among the 700 studied patients, 69 (9.9\%) had unfavorable outcomes; the oldest old group had a higher rate of unfavorable outcomes than did the non-oldest old adult patient group (23.6\% vs 5.8\%; $P<0.001$; Table 1$)$.

\section{Risk factors for unfavorable outcomes}

For all studied patients, the multivariate analysis revealed that an oldest old age, malignant solid tumor, and hepatitis during treatment were independent risk factors for an unfavorable outcome. Among the oldest old patient group, hepatitis during treatment was the only independent risk factor for an unfavorable outcome in the multivariate analysis (adjusted OR: 4.417, 95\% CI: 1.839-10.611; $P=0.001$; Table 2).

\section{Risk factors for hepatitis during RIP treatment}

The multivariate analysis, which also included HBV carriers and HCV-seropositive patients, showed that diabetes mellitus was the only independent risk factor for hepatitis not only in all patients but also in the oldest old patient group (Table 3).

\section{Hepatitis during RIP treatment}

A total of 67 of the 83 patients with hepatitis $(80.7 \%)$ had hepatitis during the first 2 months of RIP treatment. After RIP rechallenge, 58 of these patients $(69.9 \%)$ ultimately received first-line treatments containing at least two RIP component drugs. The durations between RIP treatment initiation and hepatitis onset were similar in the oldest old and the nonoldest old adult patient groups. The types and numbers of drugs that were discontinued because of hepatitis and the rechallenge success rates were also similar in both groups. Finally, the oldest old group had a significantly higher incidence of unfavorable outcomes than did the non-oldest old adult patient group in terms of hepatitis during RIP treatment (50\% vs $16.4 \% ; P=0.001$; Table 4 ).

\section{Management and outcomes after hepatitis}

In the 83 patients with hepatitis, the independent factors related to outcome in the patients were oldest old age, 
Table I Clinical characteristics of patients with tuberculosis treated with regimens containing rifampicin, isoniazid, and pyrazinamide, and the comparison analysis between the oldest old and the non-oldest old adult patient groups

\begin{tabular}{|c|c|c|c|c|}
\hline Characteristics & All $(n=700)$ & Oldest old $^{a}(n=161)$ & Non-oldest old adult ${ }^{a}(n=539)$ & $P$-value \\
\hline Female & $170(24.3)$ & $55(34.2)$ & $115(21.3)$ & 0.001 \\
\hline Male & $530(75.7)$ & $106(65.8)$ & $424(78.7)$ & \\
\hline \multicolumn{5}{|l|}{ Comorbidity } \\
\hline Diabetes mellitus & $170(24.3)$ & $33(20.5)$ & $137(25.4)$ & 0.201 \\
\hline Heart disease & $12(1.7)$ & $2(1.2)$ & $10(1.9)$ & 0.743 \\
\hline COPD & $32(4.6)$ & $13(8.1)$ & $19(3.5)$ & 0.015 \\
\hline CKD stage 5 & $19(2.7)$ & $2(1.2)$ & $17(3.2)$ & 0.271 \\
\hline DLC & $2(0.3)$ & $0(0.0)$ & $2(0.4)$ & 1.000 \\
\hline $\mathrm{HBsAg}(+)^{\mathrm{b}}$ & $65(20.1)$ & $7(9.2)$ & $58(23.4)$ & 0.007 \\
\hline Anti-HCV antibody $(+)^{c}$ & $106(33.0)$ & $26(35.6)$ & $80(32.3)$ & 0.592 \\
\hline Solid tumor cancer & $72(10.3)$ & $15(9.3)$ & $57(10.6)$ & 0.645 \\
\hline Hematological malignancies & $8(1.1)$ & $\mathrm{I}(0.6)$ & $7(1.3)$ & 0.689 \\
\hline Immunosuppression & $26(3.7)$ & $2(1.2)$ & $24(4.5)$ & 0.059 \\
\hline \multicolumn{5}{|l|}{ Constitutional symptom } \\
\hline Fever & $150(2 \mid .4)$ & $33(20.5)$ & 117 (2।.7) & 0.743 \\
\hline Body weight loss & $115(16.4)$ & $10(6.2)$ & $105(19.5)$ & $<0.00$ I \\
\hline Cold sweat & $17(2.4)$ & $3(1.9)$ & $14(2.6)$ & 0.774 \\
\hline \multicolumn{5}{|l|}{ Sites of infection } \\
\hline Upper respiratory tract & $5(0.7)$ & $\mathrm{I}(0.6)$ & $4(0.7)$ & 1.000 \\
\hline Pulmonary & 657 (93.9) & $156(96.9)$ & $501(93.0)$ & 0.067 \\
\hline Pleura & $19(2.7)$ & $4(2.5)$ & $15(2.8)$ & 1.000 \\
\hline Bone and joint & $24(3.4)$ & $10(6.2)$ & $14(2.6)$ & 0.027 \\
\hline TB spine & $16(2.3)$ & $5(3.1)$ & II (2.0) & 0.383 \\
\hline TB arthritis & $8(1.1)$ & $5(3.1)$ & $3(0.6)$ & 0.008 \\
\hline Lymph node & $12(1.7)$ & $0(0.0)$ & $12(2.2)$ & 0.078 \\
\hline Urinary tract & $12(1.7)$ & $3(1.9)$ & $9(1.7)$ & 1.000 \\
\hline Meningitis & $4(0.6)$ & $0(0.0)$ & $4(0.7)$ & 0.579 \\
\hline Pericarditis & $5(0.7)$ & $0(0.0)$ & $5(0.9)$ & 0.594 \\
\hline Anus abscess & $2(0.3)$ & $\mathrm{I}(0.6)$ & $\mathrm{I}(0.2)$ & 0.407 \\
\hline Dissemination & $28(4.0)$ & $10(6.2)$ & $18(3.3)$ & 0.103 \\
\hline \multicolumn{5}{|l|}{ Adverse effect } \\
\hline Hepatitis & $83(11.9)$ & $28(17.4)$ & $55(10.2)$ & 0.014 \\
\hline Gastrointestinal upset & $18(2.6)$ & $8(5.0)$ & $10(1.9)$ & 0.029 \\
\hline Skin rash & $34(4.9)$ & $8(5.0)$ & $26(4.8)$ & 0.940 \\
\hline Arthritis & $17(2.4)$ & $4(2.5)$ & $13(2.4)$ & 1.000 \\
\hline Hyperuricemia & $17(2.4)$ & $3(1.9)$ & $14(2.6)$ & 0.774 \\
\hline Others & $7(1.0)$ & $0(0.0)$ & $7(1.3)$ & $0.36 \mathrm{I}$ \\
\hline Total & $158(22.6)$ & $44(27.3)$ & $1 \mid 4(2 \mid .2)$ & 0.092 \\
\hline Unfavorable outcome $^{d}$ & $69(9.9)$ & $38(23.6)$ & $31(5.8)$ & $<0.00 \mathrm{I}$ \\
\hline
\end{tabular}

Notes: ${ }^{\mathrm{a}}$ Data shown represent number (\%) of subjects. ${ }^{\mathrm{b}} 324$ patients had $\mathrm{HBsAg}$ data, including 76 in the oldest old group and 248 in the non-oldest old adult patient group. c32I patients had anti-HCV data, including 73 in the oldest old group and 248 in the non-oldest old adult patient group. ${ }^{\mathrm{d} P a t i e n t s}$ who did not receive a full course of TB treatment with good clinical responsiveness and microbiological eradication, and patients who died during therapeutic course.

Abbreviations: COPD, chronic obstructive pulmonary disease; CKD, chronic kidney disease; DLC, decompensated liver cirrhosis; HBsAg, hepatitis B surface antigen; $\mathrm{HCV}$, hepatitis $\mathrm{C}$ virus; TB, tuberculosis.

malignant solid tumor, and rifampicin use. In the 28 oldest old patients with hepatitis, rifampicin use was the only factor that correlated with a good outcome in the univariate analysis (Table 5).

\section{Discussion}

In 2014, the life expectancy was 79.84 years in Taiwan. ${ }^{15}$ This is the first study focusing on the adverse effects and clinical outcomes of RIP treatment in the oldest old patients with TB. In the study, oldest old age and hepatitis during RIP treatment were independently associated with unfavorable outcome. Although the success rates of RIP rechallenge were similar in the oldest old and the non-oldest old adult patients with hepatitis, the former had a significantly higher rate of unfavorable outcome. In addition to the confounding of age, the oldest old patients tended to have unfavorable outcome in the second-line anti-TB treatment $(3 / 5,60 \%$ vs $2 / 15,13.3 \%$ ), especially those with treatment not containing 
Table 2 Risk factors for unfavorable outcome

\begin{tabular}{|c|c|c|c|c|c|c|}
\hline \multirow[t]{2}{*}{ Variables } & \multirow[t]{2}{*}{ Unfavorable ${ }^{a}$} & \multirow[t]{2}{*}{ Favorable $^{a}$} & \multirow{2}{*}{$\frac{\text { Univariate }}{P \text {-value }}$} & \multicolumn{3}{|c|}{ Multivariate } \\
\hline & & & & OR & $95 \% \mathrm{Cl}$ & $P$-value \\
\hline All patients, number & 69 & 631 & & & & \\
\hline Oldest old & $38(55.1)$ & $123(19.5)$ & $<0.001$ & 5.161 & $2.294-11.613$ & $<0.001$ \\
\hline Body weight loss & $6(8.7)$ & $109(17.3)$ & 0.068 & 1.275 & $0.374-4.374$ & 0.697 \\
\hline $\mathrm{HBsAg}(+)^{\mathrm{b}}$ & $3(8.8)$ & $62(21.4)$ & 0.084 & 0.449 & $0.126-1.599$ & 0.217 \\
\hline Solid tumor cancer & $16(23.2)$ & $56(8.9)$ & $<0.00 \mathrm{I}$ & 3.626 & $1.353-9.917$ & 0.010 \\
\hline Hepatitis & $23(33.3)$ & $60(9.5)$ & $<0.001$ & 3.482 & $1.537-7.885$ & 0.003 \\
\hline Oldest old group, number & 38 & 123 & & & & \\
\hline Solid tumor cancer & $7(18.4)$ & $8(6.5)$ & 0.049 & 3.052 & $0.972-9.587$ & 0.056 \\
\hline Hepatitis & $14(36.8)$ & $14(2.2)$ & $<0.001$ & 4.417 & $|.839-10.6| 1$ & 0.001 \\
\hline
\end{tabular}

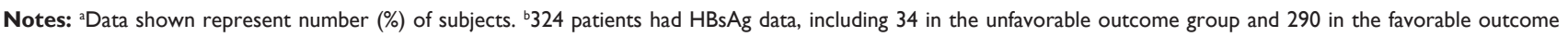
group.

Abbreviations: $\mathrm{OR}$, odds ratio; $\mathrm{Cl}$, confidence interval; $\mathrm{HBsAg}$, hepatitis $\mathrm{B}$ surface antigen.

Table 3 Risk factors for hepatitis during treatment

\begin{tabular}{|c|c|c|c|c|c|c|}
\hline \multirow[t]{2}{*}{ Variables } & \multirow[t]{2}{*}{ Hepatitis $^{\mathbf{a}}$} & \multirow[t]{2}{*}{ Non-hepatitis $^{a}$} & \multirow{2}{*}{$\frac{\text { Univariate }}{P \text {-value }}$} & \multicolumn{3}{|c|}{ Multivariate } \\
\hline & & & & OR & $95 \% \mathrm{Cl}$ & $P$-value \\
\hline All patients, number & 83 & 617 & & & & \\
\hline Male & $7 \mid(85.5)$ & 459 (73.4) & 0.026 & 1.397 & $0.639-3.055$ & 0.402 \\
\hline Oldest old & $28(33.7)$ & I33 (21.6) & 0.013 & 1.885 & $0.967-3.676$ & 0.063 \\
\hline Body weight loss & $5(6.0)$ & $110(17.8)$ & 0.006 & 0.357 & $0.120-1.063$ & 0.064 \\
\hline Heart disease & $4(4.8)$ & $8(1.3)$ & 0.043 & 4.164 & $0.975-17.780$ & 0.054 \\
\hline Diabetes mellitus & $27(33.7)$ & $143(23.2)$ & 0.062 & 2.201 & I. $145-4.229$ & 0.018 \\
\hline $\mathrm{HBsAg}(+)^{\mathrm{b}}$ & $14(23.0)$ & $51(19.4)$ & 0.532 & 1.567 & $0.765-3.208$ & 0.219 \\
\hline Anti-HCV antibody $(+)^{c}$ & $21(35.0)$ & $85(32.6)$ & 0.718 & 0.974 & $0.521-1.822$ & 0.935 \\
\hline Oldest old group, number & 28 & 133 & & & & \\
\hline Male & $25(89.3)$ & 81 (60.9) & 0.004 & 4.527 & $0.924-22.173$ & 0.062 \\
\hline Diabetes mellitus & $10(35.7)$ & $23(17.3)$ & 0.028 & 7.194 & $1.614-32.068$ & 0.010 \\
\hline $\mathrm{HBsAg}(+)^{d}$ & $2(10.0)$ & $5(8.9)$ & 1.000 & 0.993 & $0.138-7.122$ & 0.995 \\
\hline Anti-HCV antibody $(+)^{e}$ & $4(21.0)$ & $22(40.7)$ & 0.123 & 0.434 & $0.118-1.596$ & 0.209 \\
\hline
\end{tabular}

Notes: a Data shown represent number (\%) of subjects. ${ }^{\mathrm{b}} 324$ patients had HBsAg data, including $6 \mathrm{I}$ in the hepatitis group and 263 in the non-hepatitis group. ${ }^{\mathrm{c}} 32 \mathrm{I}$ patients had anti-HCV data, including 60 in the hepatitis group and $26 \mathrm{I}$ in the non-hepatitis group. ${ }^{\mathrm{d}} 76$ patients had HBsAg data, including 20 in the hepatitis group and 56 in the nonhepatitis group. ${ }^{\mathrm{e}} 73$ patients had anti-HCV antibody data, including 19 in the hepatitis group and 54 in the non-hepatitis group.

Abbreviations: $\mathrm{OR}$, odds ratio; $\mathrm{Cl}$, confidence interval; $\mathrm{HBsAg}$, hepatitis $\mathrm{B}$ surface antigen; $\mathrm{HCV}$, hepatitis $\mathrm{C}$ virus.

Table 4 Hepatitis during treatment

\begin{tabular}{|c|c|c|c|}
\hline Variables & Oldest old ${ }^{a}(n=28)$ & Non-oldest old adult ${ }^{a}(n=55)$ & $P$-value \\
\hline \multicolumn{4}{|l|}{ Duration between treatment and onset } \\
\hline$<2$ months & $23(82.1)$ & $44(80.0)$ & 0.815 \\
\hline $2-4$ months & $3(10.7)$ & $10(18.9)$ & 0.528 \\
\hline$>4$ months & $2(7.1)$ & $\mathrm{I}(\mathrm{I} .8)$ & 0.251 \\
\hline \multicolumn{4}{|l|}{ Management } \\
\hline Discontinue rifampicin & $25(89.3)$ & $52(95.6)$ & 0.400 \\
\hline Successful rechallange & $16(64.0)$ & $33(63.5)$ & \\
\hline Discontinue isoniazid & $24(85.7)$ & $49(89.1)$ & 0.727 \\
\hline Successful rechallenge & $17(70.8)$ & $34(69.4)$ & \\
\hline Discontinue pyrazinamide & $25(89.3)$ & $50(91.0)$ & 1.000 \\
\hline Successful rechallenge & $7(28.0)$ & $12(24.0)$ & \\
\hline With at least two drugs of RIP in the end & $20(71.4)$ & $38(69.1)$ & 0.826 \\
\hline Unfavorable outcome & $14(50.0)$ & $9(16.4)$ & 0.001 \\
\hline
\end{tabular}

Note: ${ }^{a}$ Data shown represent number (\%) of subjects.

Abbreviation: RIP, rifampicin, isoniazid, and pyrazinamide. 
Table 5 Risk factors for an unfavorable outcome in patients with hepatitis

\begin{tabular}{|c|c|c|c|c|c|c|}
\hline \multirow[t]{2}{*}{ Variables } & \multirow[t]{2}{*}{ Unfavorable ${ }^{a}$} & \multirow[t]{2}{*}{ Favorable $^{a}$} & \multirow{2}{*}{$\frac{\text { Univariate }}{P \text {-value }}$} & \multicolumn{3}{|c|}{ Multivariate } \\
\hline & & & & OR & $95 \% \mathrm{Cl}$ & P-value \\
\hline All patients, number & 23 & 60 & & & & \\
\hline Oldest old & $14(60.9)$ & $14(23.3)$ & 0.001 & 31.379 & $3.527-279.174$ & 0.002 \\
\hline Malignant solid tumor & $8(34.8)$ & $3(5.0)$ & $<0.001$ & II2.708 & $7.905-1,606.911$ & $<0.001$ \\
\hline Rifampicin use & $8(34.8)$ & $47(78.3)$ & $<0.001$ & 0.013 & $0.001-0.185$ & 0.001 \\
\hline Using at least two RIP drugs at the end & II (47.8) & $45(75.0)$ & 0.018 & 1.546 & $0.226-10.593$ & 0.657 \\
\hline Oldest old group, number & 14 & 14 & & - & - & - \\
\hline Malignant solid tumor & $4(28.6)$ & $0(0)$ & 0.098 & - & - & - \\
\hline Rifampicin use & $5(35.7)$ & $14(100)$ & 0.001 & - & - & - \\
\hline
\end{tabular}

Note: a Data shown represent number (\%) of subjects.

Abbreviations: OR, odds ratio; $\mathrm{Cl}$, confidence interval; RIP, rifampicin, isoniazid, and pyrazinamide; -, not applicable.

rifampicin $(3 / 3,100 \%$ vs $2 / 13,15.4 \%)$ comparing to the nonoldest old adult patients. Besides, more oldest old patients with hepatitis died before RIP rechallenge and second-line anti-TB treatment than non-oldest old adult patients $\operatorname{did}(3 / 8$, $37.5 \%$ vs $2 / 17,11.8 \%$ ). In the oldest old group, the patients with hepatitis receiving treatment containing rifampicin had similar clinical outcome compared to the patients without hepatitis (the patients with unfavorable outcome: 5/19, 26.3\% vs $24 / 133,18.0 \% ; P=0.365)$.

Hepatitis was a common side effect in standard anti-TB treatment containing RIP, and management suggestion in guidelines included discontinuation of the drugs and rechallenge after decrease of serum levels of liver enzymes. ${ }^{14,16,17}$ In this study, both oldest old and non-oldest old adult patients with hepatitis were managed according to the guidelines. In general, the patients with hepatitis receiving second-line anti-TB treatment not containing rifampicin tended to have unfavorable outcome, especially the oldest old patients. These results revealed the risk and impact of hepatitis during standard anti-TB treatment in the oldest old patients and the importance of first-line anti-TB drugs rechallenge after hepatitis, especially rifampicin.

The recommendations for TB therapy were the same for aged patients and young adults. The incidence rates of hepatitis in anti-TB treatment ranged from $2.4 \%$ to $26 \%$ in prior studies, and the hepatitis usually developed in the first 2 months of anti-TB therapy. Some studies reported that the incidence of hepatitis was positively correlated with the aging, ${ }^{6,18-20}$ but the correlation was not observed in the other studies. ${ }^{21}$ Salvadó et al compared 27 oldest old patients to 82 old age patients (65-79 years old $)^{12}$ and reported that the oldest old patients had a higher rate of hepatitis than the other groups. Our study also revealed a higher rate of hepatitis in oldest old than non-oldest old adult patients, and $\sim 80 \%$ of the cases had hepatitis in the first 2 months of
anti-TB therapy. However, multivariate analyses showed that the oldest old age was not independently associated with hepatitis, and diabetes mellitus was the only independent risk factor not only in all patients but also in the oldest old group in this study. In a systemic review, diabetes mellitus might be associated with treatment failure in patients with TB. ${ }^{22}$ Even without clinical evidence supporting the hypothesis in vivo, Wang et al reported that the hepatic cytochrome p450 2E1 activity increased in the patients with diabetes. ${ }^{23}$ Cytochrome p450 2E1 activates several hepatotoxins and contributes to hepatotoxicity in patients with TB. ${ }^{24,25}$

The association between chronic viral hepatitis and hepatitis during anti-TB therapy was controversial. In the study by Hwang et al, there was no significant association between hepatitis during anti-TB treatment and HBV carrier. ${ }^{26}$ But some studies reported that HBV carrier was a risk factor for hepatitis during anti-TB therapy. ${ }^{27,28}$ Some studies showed that patients with HCV seropositive had a higher rate of hepatitis during anti-TB therapy than those with HCV seronegative, ${ }^{29,30}$ but Liu et al reported that chronic viral hepatitis including hepatitis $\mathrm{C}$ was not significantly associated with hepatitis during anti-TB treatment. ${ }^{31}$ In our study, HBV or HCV infection was not a risk factor for hepatitis during anti-TB treatment in all patients and in the oldest old patients.

The clinical presentation of elder patients with TB might be atypical and subtle, ${ }^{7}$ which might lead to delayed diagnosis in the oldest old patients with TB. ${ }^{32}$ In a meta-analysis study comparing clinical manifestations between the younger and older patients with pulmonary TB, the older patients had lower rates of fever, sweating, and hemoptysis. ${ }^{33}$ Our study also showed that the constitutional symptoms were less common in the oldest old patient group than those in the other groups. 
García-Rodríguez et al reported that female sex and age were independently associated with extrapulmonary TB. ${ }^{34}$ In our study, extrapulmonary TB was not common either in oldest old or non-oldest old adult patient groups. However, more patients in the oldest old group had TB arthritis than those in the non-oldest old adult patient group. The invasive procedures were usually necessary in the diagnosis of extrapulmonary TB. With less enthusiasm for the invasive procedures for extrapulmonary $\mathrm{TB}$ diagnosis and more reliance on supportive care, extrapulmonary TB may be underestimated in the oldest old patients.

This study had some limitations. First, the exclusion of patients who died in the 2 months of diagnosis may result in an underestimation of the ratio of the unfavorable outcome. Second, only $\sim 40 \%$ of patients were available for hepatitis B or C seromarkers; further studies for establishing the roles of hepatitis virus seromarkers in oldest old patients were needed. Finally, the term hepatitis during the anti-TB therapy was not equivalent to the term drug-induced hepatitis.

\section{Conclusion}

In the adult TB patients with RIP treatment, oldest old age and hepatitis during treatment were associated with unfavorable outcome. For the oldest old TB patients with hepatitis during treatment, rechallenge and use of rifampicin might be beneficial to the treatment outcome.

\section{Acknowledgment}

The study was conducted independently of the funding agencies and pharmaceutical companies.

\section{Disclosure}

The authors report no conflicts of interest in this work.

\section{References}

1. World Health Organization. Global Tuberculosis Report 2015. Geneva: World Health Organization; 2015.

2. Gavazzi G, Herrmann F, Krause KH. Aging and infectious diseases in the developing world. Clin Infect Dis. 2004;39(1):83-91.

3. Kinsella K, Phillips DR. Global aging: the challenge of success. Popul Bull. 2005;60(1):1-42.

4. Ministry of the Interior, Republic of China (Taiwan). Statistical Yearbook of Interior. Taiwan: Ministry of the Interior, Republic of China (Taiwan); 2014.

5. Rajagopalan S. Tuberculosis and aging: a global health problem. Clin Infect Dis. 2001;33(7):1034-1039.

6. Leung CC, Yew WW, Chan CK, et al. Tuberculosis in older people: a retrospective and comparative study from Hong Kong. J Am Geriatr Soc. 2002;50(7):1219-1226.

7. Zecallos M, Justman JE. Tuberculosis in the elderly. Clin Geriatr Med. 2003;19:121-138.

8. Lee JH, Han DH, Song JW, Chung HS. Diagnostic and therapeutic problems of pulmonary tuberculosis in elderly patients. J Korean Med Sci. 2005;20:784-789.
9. Towhidi M, Azarian A, Asnaashari A. Pulmonary tuberculosis in the elderly. Tanaffos. 2008;7(1):52-57.

10. Packham S. Tuberculosis in the elderly. Gerontology. 2001;47(4): 175-179.

11. Rizvi N, Shah RH, Inayat N, Hussain N. Differences in clinical presentation of pulmonary tuberculosis in association with age. $J$ Pak Med Assoc. 2003;53(8):321-324.

12. Salvadó M, Garcia-Vidal C, Vázquez P, et al. Mortality of tuberculosis in very old people. J Am Geriatr Soc. 2010;58(1):18-22.

13. Lin YS, Yen YF. Determinants of mortality before start of and during tuberculosis treatment among elderly patients: a population-based retrospective cohort study. Age Ageing. 2015;44(3):490-496.

14. Philadelphia Tuberculosis Control Program. Guidelines for the Management of Adverse Drug Effects of Antimycobacterial Agents. Lawrence Flick Memorial Tuberculosis Clinic. Philadelphia: Philadelphia Tuberculosis Control Program; 1998.

15. Chang FY, Chou JH, Chuang JH, et al. Taiwan Tuberculosis Report 2013. Taiwan: Centers for Disease Control, Ministry of Health and Welfare, R. O. C. (Taiwan); 2014.

16. British Thoracic Society (BTS). Chemotherapy and management of tuberculosis in the United Kingdom: recommendations 1998. Joint tuberculosis committed of the British Thoracic Society. Thorax. 1998; 53:536-548.

17. Saukkonen JJ, Cohn DL, Jasmer RM, et al; ATS (American Thoracic Society) Hepatotoxicity of Antituberculosis Therapy Subcommittee. An official ATS statement: hepatotoxicity of antituberculosis therapy. Am J Respir Crit Care Med. 2006;174(8):935-952.

18. Baghaei P, Tabarsi P, Chitsaz E, et al. Incidence, clinical and epidemiological risk factors, and outcome of drug-induced hepatitis due to antituberculosis agents in new tuberculosis cases. Am J Ther. 2010;17(1): $17-22$.

19. Gaude GS, Chaudhury A, Hattiholi J. Drug-induced hepatitis and the risk factors for liver injury in pulmonary tuberculosis patients. J Family Med Prim Care. 2015;4(2):238-243.

20. Hosford JD, von Fricken ME, Lauzardo M, et al. Hepatotoxicity from antituberculous therapy in the elderly: a systematic review. Tuberculosis (Edinb). 2015;95(2):112-122.

21. Makhlouf HA, Helmy A, Fawzy E, El-Attar M, Rashed HA. A prospective study of antituberculous drug-induced hepatotoxicity in an area endemic for liver disease. Hepatol Int. 2008;2(3):353-360.

22. Baker MA, Harries AD, Jeon CY, et al. The impact of diabetes on tuberculosis treatment outcomes: a systematic review. BMJ Med. 2011;9:81.

23. Wang Z, Hall SD, Maya JF, Li L, Asghar A, Gorski JC. Diabetes mellitus increases the in vivo activity of cytochrome P450 2E1 in humans. Br J Clin Pharmacol. 2003;55(1):77-85.

24. Wang T, Yu HT, Wang W, Pan YY, He LX, Wang ZY. Genetic polymorphisms of cytochrome $\mathrm{p} 450$ and glutathione S-transferase associated with antituberculosis drug- induced hepatotoxicity in Chinese tuberculosis patients. J Int Med Res. 2010;38(3):977-986.

25. Lian Y, Zhao J, Xu P, et al. Protective effects of metallothionein on isoniazide and rifampicin-induced hepatotoxicity in mice. PLoS One. 2013;8(8):e72058.

26. Hwang SJ, Wu JC, Lee CN, et al. A prospective clinical study of isonizide-rifampicin-pyrazinamide-induced liver injury in an area endemic for hepatitis B. J Gastroenterol Hepatol. 1997;12:87-91.

27. Lee BH, Koh WJ, Choi MS, et al. Inactive hepatitis B surface antigen carrier state and hepatotoxicity during antituberculosis chemotherapy. Chest. 2005;127:1304-1311.

28. Wong WM, Wu PC, Yuen MF, et al. Antituberculosis drug-related liver dysfunction in chronic hepatitis B infection. Hepatology. 2000;31: 201-206.

29. Chien JY, Huang RM, Wang JY, et al. Hepatitis C virus infection increases hepatitis risk during anti-tuberculosis treatment. Int J Tuberc Lung Dis. 2010;14(5):616-621.

30. Kwon YS, Koh WJ, Suh GY, Chung MP, Kim H, Kwon OJ. Hepatitis $\mathrm{C}$ virus infection and hepatotoxicity during antituberculosis chemotherapy. Chest. 2007;131(3):803-808. 
31. Liu YM, Cheng YJ, Li YL, Liu CE, Hsu WH. Antituberculosis treatment and hepatotoxicity in patients with chronic viral hepatitis. Lung. 2014;192(1):205-210.

32. Rieder HL, Kelly GD, Bloch AB, Cauthen GM, Snider DE Jr. Tuberculosis diagnosed at death in the United States. Chest. 1991;100:678-681.

33. Pérez-Guzmán C, Vargas MH, Torres-Cruz A. Does aging modify pulmonary tuberculosis? a meta-analytical review. Chest. 1999;116: 961-967.
34. García-Rodríguez JF, Álvarez-Díaz H, Lorenzo-García MV, MariñoCallejo A, Fernández-Rial Á, Sesma-Sánchez P. Extrapulmonary tuberculosis: epidemiology and risk factors. Enferm Infecc Microbiol Clin. 2011;29(7):502-509.

\section{Publish your work in this journal}

Clinical Interventions in Aging is an international, peer-reviewed journal focusing on evidence-based reports on the value or lack thereof of treatments intended to prevent or delay the onset of maladaptive correlates of aging in human beings. This journal is indexed on PubMed Central, MedLine,
CAS, Scopus and the Elsevier Bibliographic databases. The manuscript management system is completely online and includes a very quick and fair peer-review system, which is all easy to use. Visit http://www.dovepress. com/testimonials.php to read real quotes from published authors. 